Reprinted from Flezzani, J. D., \& Benshoff, J. M. (2003). Understanding sexual aggression in male college students: The role of self-monitoring and pluralistic ignorance. Journal of College Counseling, 6, 69-79. The American Counseling Association. Reprinted with permission. No further reproduction authorized without written permission from the American Counseling Association: http://www.counseling.org/

\title{
Understanding Sexual Aggression in Male College Students: The Role of Self-Monitoring and Pluralistic Ignorance
}

\author{
Janice D. Flezzani and James M. Benshoff
}

The authors examined the relationship between self-monitoring and pluralistic ignorance and selfreported sexually aggressive behaviors by freshman and sophomore male college students. Results indicated that self-monitoring style and level of pluralistic ignorance were correlated positively with sexual aggression. The authors review relevant literature, present research findings, and discuss implications of the findings for college counselors.

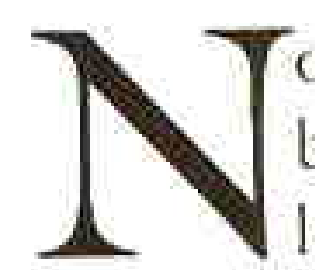

onstranger sexual assault, commonly referred to as date rape, has been documented as a serious problem on college campuses for at least three decades (Kanin, 1967). Date rape can be defined as rape that occurs when two persons are involved in a dating or casual relationship (Rapaport \& Posey, 1991). Research indicates that date rape is characterized by unique theoretical explanations, motivations for perpetration, and causal factors that distinguish it from the larger category of rape. For example, in date rape, the perpetrator and victim know each other, and when the rape occurs, they are interacting within a context in which consensual sex is a possibility and social peer support may be linked to perpetration. In addition, in date rape, the man's motivation is sex, not rape, as it is in stranger rape, in which the man's motivation is to degrade and humiliate the victim (Cowling, 1998).

Research has indicated that date rape is an underreported crime. Koss (1988) found a large disparity between the number of women who reported having been victimized (54\%) and the number of men who acknowledged having engaged in sexually assaultive behavior ( $25 \%$ ). These numbers suggest that men probably do not admit to cnough sexual aggression to account for the number of victimizations reported by women. Koss posited that men may have underestimated the amount of force and coerciveness they used or were unable to correctly interpret women's consent or resistance. Bondurant (1995) noted that women may not report being raped for several reasons, including shame, fear of not being believed, or self-blame for the event. Thus, disparities between perception of date rape by women and men may be even greater than those found by Koss.

Although date rape is considered the most extreme form of nonstranger sexual aggression, attempted rape and sexual coercion are relatively common on

Janice D. Flezzani, Department of Social Sciences. Winston-Salem State University: James M. Benshoff. Department of Counseling and Educational Development, University of North Carolina at Greensboro. The authors acknowledge the many contributions of Lloyd Bond to this study. Correspondence concerning this article should be addressed to fames M. Benshoff. Department of Counseling and Educotional Development, University of North Carolina at Greensboro,PO Box 26170, Greensboro, NC 27402-6170 (e-mail: benshoff@uncg.edu). 
college campuses (Koss, 1988). College men reported using verbal coercion, physical force of varying degrees, and efforts to intoxicate women in order to engage in sexual activity (Koss, Gidycz, \& Wisniewski, 1987). Men who engage in these behaviors may risk escalating to more severe forms of coercion. Moreover, these coercive behaviors adversely affected women's physical and psychological well-being (Koss, 1988).

Many variables have been examined as contributing factors to date rape and sexual aggression. These include acceptance of rape myths (Burt, 1980, 1991), hedonism (Crossman, 1994), misperception of cues from women (Abbey, 1991), traditional attitudes toward women (Briere, Malamuth, \& Check, 1985), differences in conflict resolution tactics (Briere \& Malamuth, 1983), previous exposure to violence in the home (McKinney, 1986), and contextual and situational factors (Abbey, 1991; Harney \& Muchlenhard, 1991). A particularly important set of variables that has been linked to date rape and other aggressive behaviors is social world influence, specifically peer influence (Crossman, 1994; Kanin, 1985; Schwartz \& DeKeseredy, 1997). Two social psychological constructs that are influenced by social and peer influences in shaping men's sexual and coercive behaviors are self-monitoring and pluralistic ignorance. There has been an increase in the amount of attention these variables have received in the literature, but little research has been conducted to identify their relationship to sexually coercive behaviors. This study, therefore, investigated these two constructs to increase understanding of how sexually aggressive behaviors can be prevented among male college students.

Self-monitoring (Snyder, 1974), the first of the two variables that we investigated, describes the extent to which individuals manage expressive behavior and self-presentation. Snyder hypothesized that individuals may monitor and control their self-presentation and expressive behaviors in order to (a) express a true emotional state, (b) conceal an inappropriate emotional state and appear to be experiencing an appropriate one, or (c) feign some emotion when they are actually experiencing a nonresponse. For example, because high self-monitors (HSMs) are concerned with social appropriateness, they regulate their behavior according to environmental cues (Snyder, 1974). HSMs usually are well liked and considered more socially adept than low self-monitors (LSMs; Snyder, Gangestad, \& Simpson, 1983). Snyder, Simpson, and Gangestad (1986) also found that HSMs had more sex partners, were younger at the time of their first sexual experience, and reported that they did not require psychological closeness or intimacy with their sexual partners. In contrast, LSMs typically relied more on internal cues to guide their behavior. Their self-presentation behaviors were more likely to reflect their personal attitudes and values, and their affective states were influenced less by their environment. For example, LSMs often chose friends whom they perceived as having similar interests, rather than seeking out those persons who were considered attractive or popular.

The second variable of interest, pluralistic ignorance, is the result of a misperception of the social norm (Allport, 1924; D. T. Miller \& Prentice, 1994; Prentice \& Miller, 1993). O'Gorman (1986) described pluralistic igno- 
rance as the "state of believing that one's private attitudes and judgments are different from those of others, even though one's public behavior is identical” ( $\mathrm{p} .333$ ). Pluralistic ignorance refers to assumptions about others' attitudes or beliefs that are mistakenly considered to be correct. For example, if an individual votes against letting an African American person join a fraternity, not because of his own prejudice but because he believes that fellow members are prejudiced, he is engaging in pluralistically ignorant behavior. In adolescence, the interplay between pluralistic ignorance and social influence may be particularly noticeable because of the documented influence of peers at this developmental stage.

Peer influence has been found to significantly affect an individual's attitudes, emotions, perceptions, and behaviors (Allport, 1968). Peer influence has also been identified as a potent factor in decisions related to adolescent smoking, drug use, and sexual activity (Newman \& Newman, 1986). During adolescence, peer group affiliation assumes heightened importance. Individual needs related to social approval, status, power, and reputation reflect the type of groups chosen for identification (Kimmel \& Weiner, 1984). On one hand, group membership may teach social skills, such as how to manage behaviors to fit in because a certain amount of conforming behavior is a necessary requirement for maintaining inclusion and acceptance by the group. On the other hand, involvement with a peer group opens individuals up to peer pressure and social influence from members of the larger group.

Date rape and other nonstranger sexually aggressive behaviors occur among an adolescent population that, from a developmental perspective, is particularly vulnerable to social, environmental, and peer influences. This vulnerability may be exacerbated when students first go to college and establish new social networks. The immediate tasks of fitting in with peers and adjusting to life away from the security of home may result in increased susceptibility to peer influence. This kind of social world influence may be particularly salient when explaining the phenomenon of date rape and other nonstranger sexually aggressive behaviors.

Self-monitoring, pluralistic ignorance, and social influence may be linked together on the basis of similarities that define the constructs. These similarities include the need for conformity, the need for social acceptance, and awareness of socially desirable behaviors. Although self-monitoring and pluralistic ignorance have not been studied within the domain of sexual aggression, a paper presented by Yeseavage and White (1989) suggested that there is a correlation between high self-monitoring and sexual aggression. Traits common to both HSMs and sexually aggressive men include an increased likelihood of engaging in promiscuous sex, having multiple sexual partners, having one's first sexual experience at a younger age as compared with the norm, and not requiring psychological closeness or intimacy for sex (Snyder et al., 1986).

Our study was a preliminary investigation of the proposed theoretical relationship between self-monitoring and pluralistic ignorance as factors that may be related to sexually aggressive behaviors in college men. The study is based 
on the hypothesis that these two constructs are conceptually related and may help to explain nonstranger sexual aggression and coercion. Specifically, we investigated the following hypotheses: (a) HSMs would self-report engaging in higher levels of sexually aggressive and coercive behaviors as compared with LSMs, and (b) college men who scored higher on pluralistic ignorance would self-report higher levels of aggression and coercion than did college men who scored lower on pluralistic ignorance.

\section{Method}

\section{Participants}

The sample of research participants was drawn from freshman and sophomore men $(N=120)$ attending a midsized public university in the southeastern United States. Traditional-aged (18-20 years) freshman and sophomore students were chosen based on the speculation that a developmental component may influence pluralistically ignorant thinking among students, with younger students being more vulnerable to norm misperception (Schwartz \& DeKeseredy, 1997). Because O'Gorman (1986) suggested that pluralistic ignorance is more likely to occur in an environment that is conducive to the misrepresentation of private beliefs, the sample in this study was drawn from male students who were living in residence halls on campus. The rationale for this was that men who live together in the close quarters of a residence hall would be more strongly and consistently influenced by their peer groups than would college men who lived off campus and, thus, spent typically less time together as a group. Sixty-two percent of the participants were Caucasian, $33 \%$ were African American, 3\% were Hispanic, and 2\% were Asian American.

\section{Instruments}

Three instruments, the Self-Monitoring Scale (Snyder, 1974), the Perceptions of College Student Behaviors Scale (PCSBS; created for this study), and the Sexual Experiences Questionnaire (SEQ; White \& Hoecker, 1995) were used in this study, in addition to a demographic questionnaire.

The Self-Monitoring Scale (Snyder, 1974) is a popular personality measure that examines individual differences in self-control of expressive behaviors. This instrument consists of 25 items determined to be internally consistent with the self-monitoring construct (Snyder, 1974). The Self-Monitoring Scale has a Kuder-Richardson 20 reliability of .70 and a test-retest reliability of .83 ( $d f=$ $51, p<.001,1$-month time interval; Snyder, 1974). Correlations between selfmonitoring and related, but conceptually distinct, individual differences measures such as the Marlowe-Crowne Social Desirability Scale (Crowne \& Marlowe, 1964) provide evidence for its discriminant validity (Snyder, 1974). Despite criticisms of self-monitoring as a construct (e.g., Briggs \& Cheek, 1988; Lenox, 1988), the Self-Monitoring Scale continues to be used widely in social psychology research. 
The PCSBS (Flezzani, 2001) was designed to measure level of pluralistic ignorance related to men's beliefs about the likelihood of peers engaging in several negative behaviors thought to be common on college campuses. Although pluralistic ignorance has been recognized widely as a social psychological phenomenon, there has been little empirical research on the construct. Before the development of the PCSBS, no specific seale had been constructed to measure pluralistic ignorance. This may be due, in part, to the fact that pluralistic ignoranee has been shown to be associated with behaviors across several domains, thus necessitating the creation of an instrument for each situation.

The SEQ (White \& Hoecker, 1995) was used in this study to measure sexual aggression and coercion. The SEQ is a modified version of the Sexual Experiences Survey (SES; Koss \& Oros, 1982), the instrument most commonly used to measure sexual perpetration on college campuses. In the modified SEQ, respondents are asked to label the frequency with which they engage in each of the behaviors listed in the SES (e.g., flattery, verbal pressure, use of alcohol and/or drugs, threats, and physical force). In addition, respondents are asked to identify some behaviors that could be considered as less severe forms of coercion (c.g., threatening to break up with a woman if she did not engage in intercourse, telling a woman he loved her just to engage in intercourse). The modified scale also distinguishes between such behaviors as purposefully giving a woman drugs/alcohol to obtain sex and trying to obtain sex with a woman who was already intoxicated. The method used in the modified scale has yielded continuous measures of sexual aggression and coercion that correlate highly with scores obtained on the SES (White, Donat, \& Humphrey, 1996).

Through consultation with experts who have written about pluralistic igno rance or have used the construct in their own research, 11 behaviors were identified as being present on college campuses and having psychological reality for college students. The PCSBS assesses pluralistic ignorance, using a format similar to that used by other researchers in the ficld (e.g., Cohen \& Shotland, 1996; D. T. Miller \& Prentice, 1994). Historically, validity for this construct has been established by clearly stating the definition of pluralistic ignorance and then stating how it will be measured (Prentice \& Miller, 1993). Construct validity for the PCSBS was determined using a process of expert review and recommendations. An acceptable level of internal consistency reliability was also established with the 11 PCSBS items (Cronbach's alpha $=.85$ ).

The PCSBS consists of two subscales. The Others subscale asks the respondent to rate the likelihood of peers engaging in certain behaviors, and the Self subscale asks the respondent to rate his own likelihood of engaging in the same behaviors, thus setting a "perceived" and "actual" norm. Participants in the present study were asked to rate their beliefs about behaviors of the typical college man. Each man was then asked to assess the likelihood that he would engage in these behaviors. Questions regarding the likelihood of their peers engaging in sexual aggression and their own likelihood of engaging in these behaviors were embedded in the instrument to disguise intent. The 
PCSBS total score was calculated by averaging the 7-point Likert-type scale items on both subscales.

\section{Procedure}

A table was set up in the lobby of residence halls, and volunteer participants were asked to complete three instruments: the PCSBS (Flezzani, 2001), the Self-Monitoring Scale (Snyder, 1974), and the SEQ (White \& Hoecker, 1995). The Self-Monitoring Scale and the PCSBS were presented in counterbalanced order, with the SEQ always being presented last. Respondents who agreed to participate were informed that this study would investigate dating behaviors, were told that their answers would be completely confidential and that data would be aggregated for data analysis, and were thanked for their participation. After completing the three instruments, participants were given a debriefing statement that explained the purpose of the study.

\section{Results}

Analyses of variance (ANOVAs), Tukey's post hoc comparisons, and Pearson product-moment correlations were used to explore the proposed theoretical relationships between self-monitoring style, pluralistic ignorance, and self-reported nonstranger sexual aggression and coercion. Preliminary analyses of the distribution of scores indicated nonnormal distributions, suggesting that analyzing the data in groups would be better than using continuous scores and performing regression analyses. Dividing self-monitoring scores trimodally has been done previously in an analysis by M. L. Miller and Thayer (1988). Distribution of scores on the Self-Monitoring Scale and the Self and Others subscales of the PCSBS was divided into more or less homogeneous high, medium, and low groups.

The first hypothesis that HSMs would self-report higher levels of sexual aggression when compared with low and medium self-monitors was supported, with HSMs engaging in significantly more sexually aggressive behaviors ( $n=$ $32 ; M=44.38, S D=15.34)$ than their low $(n=30 ; M=30.70, S D=5.01)$ and medium $(n=38 ; M=36.44, S D=10.28)$ counterparts $(F=11.93, p<.0001)$. Post hoc analysis revealed a statistically significant difference between LSMs and HSMs (mean difference $=13.68, p<.0001$ ). The difference between LSMs and medium self-monitors was not statistically significant (mean difference $=6.81, p=.122)$. Examination of the Pearson product-moment correlation between the Self-Monitoring Scale and the SEQ $(r=.43, p<.001)$ revealed that approximately $18 \%$ of the variance in self-reported sexual coercion and aggression could be accounted for by self-monitoring style.

Results also indicated that men who scored higher on pluralistic ignorance reported higher levels of sexual aggression and coercion than did men who had lower pluralistic ignorance scores, a finding that supports our second hypothesis in this study. The correlation between pluralistic ignorance and selfreported sexual coercion and aggression was $r=0.31(p<.01)$. Participants 
were divided into high, medium, and low groups based on their responses on the Others subscale of the PCSBS, with the resulting ANOVA across groups on the SEQ revealing significant differences $(F=5.20, p<.007)$. Post hoc com parisons indicated that men who reported a high level of pluralistic ignorance differed significantly (mean difference $=8.93, p<.005$ ) in their tendency to engage in sexually coercive and aggressive behaviors as compared with men who displayed relatively lower levels of pluralistic ignorance. The post hoc mean differences between men who displayed high versus medium levels of pluralistic ignorance were not significant (mean difference $=5.02, p=.20$ ).

Finally, the interaction effect of high self-monitoring with high pluralistic ignorance on sexually aggressive behaviors was found to be statistically significant $(F=5.79, p=.004)$. Post hoc comparisons showed that the group with the combination of high self-monitoring and high pluralistic ignorance reported significantly more sexually aggressive behaviors when compared with all other groups in this study. This powerful interaction effect supports the
two primary hypotheses.

\section{Discussion}

The purpose of this study was to examine the theoretical relationship between self-monitoring, pluralistic ignorance, and sexually coercive and aggressive behaviors in the nonstranger relationships of college men. Results indicated that self-monitoring style and pluralistic ignorance may be significant social world factors in nonstranger sexual aggression. On the basis of a review of the literature on sexual aggression among acquaintances, selfmonitoring, and pluralistic ignorance, we predicted that male college students with high self-monitoring styles would tend to self-report higher levels of coercive and aggressive behaviors. We also predicted that men who displayed higher levels of pluralistic ignorance would tend to self-report more aggressive and coercive behaviors. Findings tended to support both hypotheses. In addition, a strong interaction effect was found between high selfmonitoring, high pluralistic ignorance, and sexually aggressive behaviors.

Past research has not specifically linked self-monitoring style to sexually aggressive behavior. However, researchers have found that HSMs tended to date more, have more sexual partners, have more uncommitted sex, and engage in sexual activity at an earlier age as compared with LSMs. Yescavage and White (1989) noted that these factors were common to both HSMs and convicted sexual offenders. Our results support their findings that HSMs tended to report higher levels of nonstranger sexually aggressive and coercive behaviors
than did LSMs.

Although the concept of pluralistic ignorance has been observed and discussed by social psychologists and sociologists (c.g., Katz \& Allport, 1931; O'Gorman, 1986; Prentice \& Miller, 1993), pluralistic ignorance as a distinct phenomenon has not been researched extensively. Although pluralistic ignorance has not been linked specifically to sexual aggression before this study, the con- 
struct has been discussed as being a factor in peer-supported sexual aggression (Schwartz \& DeKeseredy, 1997) and examined as a factor influencing expectations for sexual intercourse in dating relationships (Cohen \& Shotland, 1996). There were several limitations in this study, including instrumentation requiring self-report, retrospective recall, lack of nonrandom sampling, and the small number of sexually aggressive and coercive college men included in the study. This investigation required the researcher (the first author) to develop an instrument to measure pluralistic ignorance because no psychometric scale had been developed to measure the construct before this study was conducted. The fact that participants in this study did not report a high level of sexually aggressive and coercive behaviors may be due to several factors. For example, men may be more reluctant to admit to engaging in these behaviors because the media attention that has focused on the problem of sexual aggression on college campuses in the last few years may have increased their awareness of society's negative view of these behaviors. It is also possible that men in this study actually were engaging in less sexually aggressive behaviors than men on other campuses. Because of the low number of sexually aggressive men, analyses included all nonconsensual sexual behaviors, even if they reflected a relatively low level of negative behavior. For example, the act of lying to a woman to obtain sex was considered to be coercive behavior for purposes of the analyses in this study. The lack of variance in the sample, however, presents a significant limitation and suggests the need to replicate this study with a larger and more diverse sample.

\section{Implications for Practice}

Results of this study support the idea that social world influence, specifically peer pressure and faulty beliefs about peers' behaviors and attitudes, may lead to coercive sexual behaviors. These results may have implications for prevention strategies. Presently, many prevention programs focus on increasing empathy for victims, because lack of empathy has been associated with self-reported likelihood of engaging in sexually aggressive behavior (Dietz, Blackwell, Daley, \& Bentley, 1982; Edidio \& Robertson, 1981). Although some success in using empathyinduction techniques in prevention has been demonstrated (e.g., Foubert, 2000), the overall success of this approach to rape prevention remains unclear. Hanson and Gidyez (1993) suggested that men find it difficult to feel empathy for women because contemporary culture supports the idea of blaming women; thus, if society supports women's culpability, it may be difficult for some men to be sympathetic toward women and the issues that concern them. Furthermore, results of this study suggest that for some men (e.g., HSMs), it may be necessary to help them develop a more realistic understanding of the norms and expectations for behavior on campus, in addition to any empathy-induction efforts.

Prevention strategies that address the possible negative effects of peer pressure and highlight the existence of faulty beliefs about peers' behaviors and attitudes may be useful in deterring perpetrators. Because HSMs seem to be 
concerned with social appropriateness, programs in which peers express negative attitudes toward aggression may prove to be somewhat compelling for these individuals. College counselors could effectively use psychoeducational and other group experiences, including outreach interventions with groups, to help male students discuss and demystify attitudes toward sexual aggression and women, in general.

The overwhelming presence of pluralistic ignorance found in this study, combined with the fact that social attitudes and beliefs are more changeable than personality traits, suggests prevention strategies that are worth exploring. For example, presentations that highlight the fact that individuals often misperceive the sexual norm and that sexually aggressive behavior is not the norm on campus or in society could be useful. In addition, the overwhelming presence of pluralistic ignorance suggests that prevention efforts should focus on confronting peers who express adherence to rape-supportive beliefs. These kinds of interventions may be particularly needed with college men who are involved with athletics and fraternities, because these all-male activities may create an insular culture in which myths about women and sexual activity can flourish.

The topic of prevention is especially relevant for counselors because the field historically has supported the prevention of psychological distress (Ivey, 1976). Unfortunately, research on the prevention of sexual aggression has not been included as part of the core counseling literature (Betz \& Fitzgerald, 1993). Appropriately trained counselors could have much to offer college men in terms of prevention programs. For example, college counselors could present prevention programs during freshman orientation that addressed the presence and possible negative effects of pluralistic ignorance. Such programs could empower freshmen, at the beginning of their college experience, to question assumptions that they may hold about what is happening on campus and help orient them to desirable, socially acceptable standards of behavior at their school. This would be prevention at its best, helping to prepare male students from the beginning of their college careers to deal realistically with critical issues of social acceptance and behavioral norms.

\section{References}

Abbey, A. (1991). Acquaintance rape and alcohol consumption on college campuses: How are they linked? Journal of American College Health, 39, 165-169.

Allport, F. H. (1924). Social psychology. Boston: Houghton Mifflin.

Allport, F. H. (1968). The historical background of modern social psychology. In G. Linzey \& E. Aronson (Eds.), The handbook of social psychology Vol. I (2nd ed., pp. 1-80). Reading, MA: Addison-Wesley.

Betz, N. E., \& Fitzgerald, L. F. (1993). Individuality and diversity: Theory and research in counseling psychology: Annual Rewicw of Psychology, 44, 343 -381.

Bondurant, A. B. (1995). Universty women's acknowledgment of rape: Individual, interpersonal, and socul factors. Unpublished doctoral dissertation, University of North Carolina at Greensboro.

Briere, 1., \& Malamuth, N. (1983). Self-reported likelihood of sexually aggressive behavior: Attitudinal vs, sexual explanations. Journal of Research in Personality, 17, 315-323. 
Briere, I., Malamuth, N., \& Check, I. V. (1985). Sexuality and rape-supportive beliefs, International Journal of Women's Studics, 8, 398-403.

Briggs, S. R., \& Cheek, J. M. (1988), On the nature of self-monitoring: Problems with assessment, problems with validity. Journal of Personality and Social Psychology, 54, 663-678.

Burt, M. R. (1980). Cultural myths and supports for rape. Journal of Personality and Social Psychology, 38, 217-230.

Burt, M. R. (1991). Rape myths and acquaintance rape. In A. Parrot \& L. Bechoffer (Eds.), Acquaintance rape: The hidden crime (pp, 26-40). New York: Wiley.

Cohen, L., \& Shotland, L. R. (1996). Timing of first sexual intercourse in a relationship: Expectations, experiences and perceptions of others. The fournal of Sex Research, 33, 291-299.

Cowling, M. (1998). Date rape and consent. Brookficld, CA: Ashgate.

Crossman, L. L. (1994, January), Date rape and sexual aggression in college males: Incidence and the involvement of impulsivity, anger, hostility, psychopathology, peer influence and pornography use. Paper presented at the annual meeting of the Southwest Educational Research Association, San Antonio, TX.

Crowne, D. P., \& Marlowe, D. (1964). The appropal motive: Studies in evaluatipe dependence. New York: Wiley.

Dietz, S. R., Blackwell, K, Daley, P. \& Bentley, B. (1982), Measurement of empathy toward rape victims and rapists. Journal of Personality and Sacial Psychology, 43, 372-384.

Edidio, R. K., \& Robertson, D. E. (1981). Rape awareness for men. Journal of College Stwdent Depelopment, 22, 455-456.

Flezzani, J. D. (2001). The role of self-monitoring and pluralistic ignorance in understanding sexual aggression and coercion in college males. Unpublished doctoral dissertation, University of North Carolina at Greensboro.

Foubert, J. D. (2000). The longitudinal effects of a rape prevention program on fraternity men's attitudes, behavioral intent, and behavior. Journal of American College Health, 48, 158-163.

Hanson, K. A., \& Gidycz, C. A. (1993). Evaluation of a sexual assault prevention program. foumal of Consulting and Clinical Psychology, 61, 1046-1052.

Harney, P. A., \& Muehlenhard, C. L. (1991). Factors that increase the likelihood of victimization. In A. Parrot \& I. Bechhofer (Eds.), Acquaintance rape: The bidden crime (pp. 150 -
175). New York: Wiley.

Ivey, A. (1976). Invited response: The counselor as teacher. Personnel and Guidance Journal,
$54,431-434$. Kanin, E. J. (1967). Reference groups and sex conduct nom violations. The Sociologital Quarterly,
8, 495-504.

Kanin, E. J. (1985). Date rapists: Differential sexual socialization and relative deprivation. Archives of Sexual Behavtur, 14, 219-231.

Katz, D., \& Allport, F. H. (1931). Student attinudes. Syracuse, NY: Craftsman. Kimmel, D. C., \& Weiner, I. B. (1984). Adulescence: A developmental transition. Hillsdale, NJ:
Erlbaum.

Koss, M. P. (1988). Hidden rape: Sexual aggression and victimization in a national sample of higher education. In M. E. Odem \& J. Clay-Warner (Eds.), Confronting rape and sexual aggressiun: Worlas of momen (pP. 51-69). Wilmington, DE: SR Books/Scholarly Resources.

Koss, M. P., Gidycz, C. A., \& Wisniewski, N. (1987). The scope of rape: Incidence and prevalence of sexual aggression and vietimization in a national sample of higher education students. Jonrnal of Cominsing and Clinical Psychology, 55, 162-170.

Koss, M. P, \& Oros, C. (1982). Sexual experiences survey: A research instrument investigating sexual aggression and victimization. Jomonal of Consulting and Clinical Psycboligy, 50, 455-457. Lenox, R. (1988). The problem with self-monitoring. A two-sided seale and a one-sided theory.
Journal of Personality Assessment, $52,58-73$.

Mckinney, K. (1986). Measures of verbal, physical, and sexual dating violence by gender. Free Inguiry in Creative Sociology, 14, 55-60 Miller, D. T., \& Prentice, D. A. (1994). The self and the collective, Personality and Socinl
Psychology Bulletin, 20,451-453. 
Miller, M 1. \& Thaver, I F (1988) On the nature of self monitorimg: Relationships with

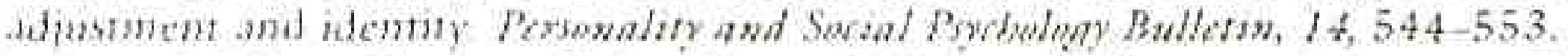

Newman, B . . \& Newman, P R. (1980) Adulestont deviopment. Columbus, OH Merrill.

O'Gorman, H I (1986). The discovery of pluralistic ignorance: An ironic lesson. fottrnal of the flistery of the fichawaral Sctene, 22, 333-347.

Prentice, 1) A, \& Miller, D T (1993, Pluralistic ignorance and alcohol use on campus: Some conseguences of misperceiving the social nom. fournal of Personality and Soctal Psydisilugy, 0.243-250.

Ripaport, L R. \& Posey, C D. (1991) Sexually coercive college males. In A. Parrot \& L.

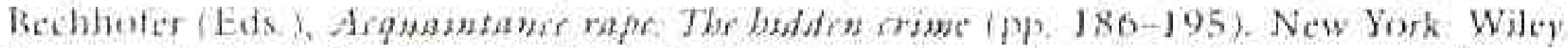

Selwartz, M D. \& DeKeseredy W S (1997) Sexalat assate an the college campus. The role of peor sutport Thousand Oaks, CA Sage

Snyder. M (1974). Self monitoring of expressive belavior fournal of Persomality and Socal Pswdolony, 30, 526-537

Snyder, M. G.ungestad, S, \& Simpson, I. A (1983). Cheosing friends as activity partuers: The role of self monitoring fournat of Persomality atud Soctal Psycholugy and Human Sexualit $\gamma, 45,1061-1072$

Snyder. M, Simpson, I A, \& Gangestad, S (19S6) Personality and sexual redations foumal of Personality and Socint Psychotony, 51, 181-190.

Whate, I W. Donat, P I.., \& Humphrey, I A. (1996). An ex.mination of attitudes underly.

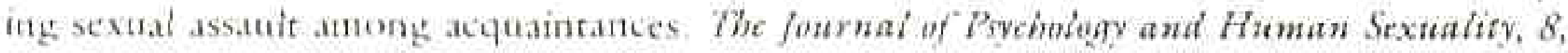
$27-48$

Whate, I W. E Hoceker, K. (1995). (Reliability and validity data for a revised Sexual Experienees Survey| Linpublished raw d.at Greensboro, NC: University of North Carolinat at Girecenstiraro.

Yestavage, I. M, \& White, 1. W, 1989, Marchi Relatmg self monitoring and sexual agares ran Paper presented a the annual mecting of the Sourlieastern Psychological Association, Washington, DC 